\title{
O PAPEL DO SINASEFE NAS POLÍTICAS DE EDUCAÇÃO PROFISSIONAL E O DOCUMENTO "REDE FEDERAL DE EDUCAÇÃO TECNOLÓGICA: ONDE ESTAMOS E O QUE QUEREMOS"
}

\author{
Shilton Roque dos Santos, Ronaldo Nascimento Naziazeno \\ Instituto Federal de Educação, Ciência e Tecnologia do Rio Grande do Norte, Instituto \\ Federal de Educação, Ciência e Tecnologia da Bahia \\ DOI: 10.15628/rbept.2019.7394
}

Artigo submetido em jun/2018 e aceito em dez/2018

\begin{abstract}
RESUMO
O presente artigo tem como objetivo analisar as contribuições do Sindicato Nacional dos Servidores da Educação Básica, Profissional e Tecnológica (SINASEFE), às discussões sobre Educação Profissional, e o seu papel nas movimentações políticas nesse campo num cenário de mudanças políticas, governos e nova institucionalidade da Rede Federal. Essa análise se dará historicizandoos movimentos das políticas de Educação Profissional no nosso Brasilno último circuito histórico e apresentando as propostas do Sinasefe à esse campo, comparando as recentes Resoluções do Sindicato, constantes do documento "Rede Federal de Educação Tecnológica: Onde estamos e o que queremos" com as diretrizes expostas no artigo "As Políticas de Educação tecnológica para o Brasil no Século XXI - Reflexões e Considerações do Sinasefe" (GUIMARÃES; SILVA, 2010), compreendendo a diferença de tempo histórico e alcance das proposições entre estes, e se propondo a atualizar o registro acadêmico das proposições dos trabalhadores da educação profissional.
\end{abstract}

Palavras-Chave: Educação Profissional. Sindicato. Trabalhadores. SINASEFE.

\section{THE ROLE OF SINASEFE IN THE POLICIES OF PROFESSIONAL EDUCATION AND THE DOCUMENT "FEDERAL NETWORK OF TECHNOLOGICAL EDUCATION: WHERE WE ARE AND WHAT WE WANT"}

\begin{abstract}
This article aims to analyze the contributions of the National Union of Servers of Basic Education, Professional and Technological (SINASEFE), to the discussions on Professional Education, and its mission in the political movements in this field in a scenario of political changes, governments and new institutionality of the Federal Institutions. This analysis will historicize the movements of the policies of Professional Education in Brazil in the last historical circuit and presenting the proposals of the Sinasefe to that field, comparing the recent Resolutions of the Union, included in the document "Rede Federal de EducaçãoTecnológica: Ondeestamos e o quequeremos" with the guidelines set forth in the article "As Políticas de Educaçãotecnológica para o Brasil no Século XXI - Reflexões e Considerações do Sinasefe"(GUIMARÃES; SILVA, 2010), understanding the difference of historical time and reach of propositions between them, and proposing to update the academic record of the propositions of workers in professional education.
\end{abstract}

Keywords: Professional Education. Trade Union. Workers. SINASEFE. 


\section{CONSTRUINDO O OBJETO DE ESTUDO}

Em um primeiro momento cumpre justificar a opção conceitual pela demarcação no tópico introdutório, pois ao aderir a concepção de objeto construído (DEMO, 2012) estamos previamente informando que o presente trabalho se fez a partir de uma relação dialética entre sujeito e objeto, entre pesquisador e sua pesquisa, apesar dos esforços em objetivação, mas assumindo que na análise da realidade feita por este artigo trazemos marcas de quem o escreve. Tal destaque é demasiado importante diante da conjuntura sociopolítica do Brasil no período em que é escrito, onde correm no Congresso Nacional projetos como o Escola sem Partido e a Lei da Mordaça ${ }^{1}$.

Feitas tais considerações, atemo-nos ao objeto de estudo, que será o documento advindo do $9^{\circ}$ Seminário Nacional de Educação (SNE) do Sindicato Nacional dos Servidores da Educação Básica, Profissional e Tecnológica (SINASEFE), aprovado em Plenária, que tem como título "Rede Federal de Educação Básica Profissional e Tecnológica: onde estamos e o que queremos", que apresenta as propostas do referido sindicato para a Rede Federal $^{2}$ e a Educação ofertada por esta.

Tal análise será realizada a partir não apenas do documento, mas considerando a produção científica já realizada outrora, em circuito histórico distinto, com destaque para o artigo "As Políticas de Educação tecnológica para o Brasil no Século XXI - Reflexões e Considerações do Sinasefe", produzido por Guimarães e Silva (2010), que apesar de publicado em 2010, apresentam um quadro de análise e diretrizes anterior a nova institucionalidade assumida pela Rede Federal hoje, qual seja, a dos Institutos Federais, bem como centra sua análise de totalidade nas mudanças ocorridas entre o fim dos Governos neoliberais do PSDB e início do período neodesenvolvimentista dos governos do PT.

1Projeto de Lei Do Senado o 193 de 2016.

2A Rede Federal de Educação Profissional, Científica e Tecnológica é um conjunto de Instituições Públicas constituída pelos atuais Institutos Federais, Colégio Pedro II e dois Centros Federeis de Educação Tecnológica. Tal rede apesar de utilizar o nome oficial a partir da constituição dos Institutos Federais tem uma tradição de mais de 100 anos na oferta da Educação Profissional, tendo seu marco inicial real em 1909 com a criação das Escolas de Aprendizes e Artífices. 
Nós somamos a caracterização de Alves (2014), que define o neodesenvolvimentismo como sendo um novo modo de desenvolvimento capitalista no Brasil apoiado numa frente política composta, por um lado, pela grande burguesia interna constituída pelos grandes grupos industriais e o agronegócio exportador - todos beneficiados pelo aumento das exportações focado numa agressiva política de financiamento através do BNDES, voltados para promover as empresas e os investimentos brasileiros no exterior; por outro lado, pelas camadas organizadas do proletariado brasileiro e setores populares - incluindo o subproletariado pobre, beneficiados pelo crescimento da economia, redução do desemprego aberto e formalização do mercado de trabalho, oferta de crédito para dinamizar o mercado interno; aumento do gasto público e políticas de transferência de renda via programas sociais (Bolsa-família, Minha Casa Minha Vida, Luz para Todos, etc).

É um modo que encerra sérias contradições de interesse sociais e só pode prosperar em um momento muito particular na história recente brasileira, em condições econômicas favoráveis. O desfecho histórico, entretanto, foi a subtração de direitos e uma grave crise econômica tendo inclusive resultado no impeachmentda presidente petista, Dilma Roussef.

Motivados pelo entendimento que ciência é um processo, e de que não podemos construir posições definitivas diante da necessidade de superação (DEMO, 2012), a partir do enfoque dialético, propomos analisar as mudanças, avanços, permanências e retrocessos nas propostas do SINASEFE para a educação tecnológica, entendendo que os movimentos da classe-que-vivedo-trabalho (ANTUNES, 2000) são de extrema importância para a compreensão das ações do homem enquanto sujeito histórico, bem como podem constituir importante base para as mudanças políticas e sociais pautadas pelas camadas que há séculos gritam por emancipação.

\section{TOTALIDADES: DO CONTEXTO POLÍTICO E ECONÔMICO AO INSTITUCIONAL}

Aprendemos com as lições de Leandro Konder que para fazermos análises com base no materialismo histórico dialético é necessário considerar 
que a realidade se apresenta em diversos níveis de totalização. De forma simples e direta, em uma de suas obras mais didáticas, ele exemplifica tal análise como num movimento espiral que vai e volta do fenômeno mais específico ao mais geral (KONDER, 1998). Em outros termos, é necessário estabelecer a relação entre o conjuntural e o estrutural e entender o objeto como parte dessa totalidade (FRIGOTTO, 2011).

Marx (2008) que funda essa forma de fazer ciência, apresenta esse método como um caminho que parte da análise do concreto, da realidade dada, enquanto fenômeno, representação caótica de um todo, até chegarem determinações mais simples, conceitos mais abstratos, retornando a análise, então, ao ponto da partida, que será agora uma totalidade, concreta e rica de determinações. Indo da aparência à essência do objeto pesquisado.

Com esta metodologia de análise, recortamos o tempo histórico entre o 2003 e 2015, período de mudança de governo na esfera federal e que marca uma série de contradições em nossa conjuntura.

O trabalho supracitado de Guimarães e Silva (2010), que trata das diretrizes do Sinasefe para Educação Tecnológica pauta sua análise a partir do processo de avanço das políticas neoliberais implementadas pelo governo Fernando Henrique Cardoso (1994-2002) e seus tensionamentos com as organizações da sociedade contrárias a essa pauta política, incluindo aquelas que discutiam as políticas educacionais. Nesse contexto, encerra sua leitura e apresenta as diretrizes formuladas pelos trabalhadores da educação profissional da base do sindicado em questão construídas um período de recuperação econômica com avanços em diversos campos, carece então analisarmos como esse grupo de trabalhadores, organizados naquela institucionalidade, responde através de um programa político as demandas do período atual.

A década de 90, que politicamente no Brasil se encerra em 2003 foi marcada pelo aumento da desigualdade social, pouco crescimento econômico, privatizações e retrocesso político, principalmente levando em conta os debates que afloravam nos campos progressistas desde o final da ditadura militar. 
Sob a batuta de Fernando Henrique Cardoso, do PSDB, e atendendo às recomendações e formulações do FMI, a educação no Brasil sofreu duros golpes que frearam o avanço pugnado por aquele campo progressista.

Para além do cortes de recursos, da questão econômico-material, o retrocesso na área da educação também se deu no campo da concepção, onde dois acontecimentos são marcantes. O primeiro é a aprovação do substitutivo da Lei de Diretrizes e Bases da Educação, uma LDB minimalista (RAMOS; FRIGOTTO; CIAVATTA, 2005) é posta no lugar do projeto amplamente discutido pelos diversos segmentos da sociedade. O segundo é a edição do Decreto $n^{\circ}$ 2208/97, que separou a formação básica do Ensino Médio da Educação Profissional, o que representou um duro golpe ao acúmulo de debates sobre a possibilidade de uma educação com formação integral pautada nos princípios da politecnia (SAVIANI, 2003).

Esse é o quadro que marca a transição para o novo período iniciado em 2003 pelo governo do Partido dos Trabalhadores, alçado ao poder sob o lema "A esperança venceu o medo" e pelas forças progressistas do país que tinham como objetivo alterar o projeto societário que engendrara as reformas neoliberais anteriormente mencionadas. Todavia, sem esquecer do enfoque da nossa análise - que tem centralidade nas contradições como movimentos das transformações - o período que passa a ser analisado é marcado por continuidades e descontinuidades do anterior.

No campo político e social, o governo do PT apresentou movimentos de avanços com a implantação e ampliação de diversos programas sociais de combate à pobreza, aliado a uma política de aumento real do salário mínimo, redução do desemprego e em um primeiro momento fortalecimento da máquina púbica em latente contradição ao desmonte efetivado pelo governo anterior.

Entretanto, apesar dos avanços mencionados, o projeto societário duramente implementado no governo anterior não fora alterado diante da tentativa de conciliação dos interesses que se tornou a grande marca do governo do PT, ou seja, houve continuidade nas políticas macroeconômicas do período anterior, aproveitando o momento de crescimento econômico para investir também na melhoria das condições de vida de parte da população, 
sem atingir a radicalidade necessária para efetivamente reduzir as desigualdades no país.

Nesse sentido, apesar do aumento nos indicadores econômicos como o Produto Interno Bruto (PIB), não houve significativo aporte de recursos em áreas de grande demanda da sociedade, como educação e saúde, pois a já mencionada continuidade nas políticas macroeconômicas apresentava como uma das prioridades a política do superávit primário para fins de pagamento da dívida pública.

Moura (2013) nos apresenta a partir de dados do próprio IBGE que efetivamente não houve políticas redistributivas, transferência de renda das camadas mais ricas para as mais pobres, pois no comparativo da distribuição de renda entre 2003 e 2010, a camada dos $10 \%$ mais ricos se manteve quase inalterada, sendo as maiores alterações entra a camada dos 50\% mais pobres que aumentou seus rendimentos e a camada dos $40 \%$ intermediários que reduzira seus rendimentos (MOURA, 2013).

No campo da educação, a transição de governo foi também recebida com esperança principalmente na perspectiva de redução do dualismo histórico entre a educação ofertada aos filhos das camadas populares, marcada pelo tecnicismo e voltada para os interesses do mercado de trabalho, e a educação dos filhos das classes mais abastadas tradicionalmente voltada para a condução destes à academia formação para a direção da sociedade.

O debate sobre a possibilidade de uma educação voltada a formação integral parecia ganhar terreno na disputa política, e os grupos progressistas envolvidos na discussão da Educação Profissional propunham a superação do Decreto $n^{\circ} 2208 / 97$, que retirara ainda mais a identidade do ensino médio, e as possibilidades das camadas populares, que passaram a estudar em "escolas públicas que nem conseguem reproduzir o academicismo da escola privada nem, majoritariamente, forma para atividades complexas dos do mundo do trabalho" (MOURA, 2013a, p. 112).

Dessa forma, em 2004, fora editado um novo Decreto o $n^{\circ} 5154$ que revogara o anterior e possibilitava a integração entre ensino médio e 
educação profissional, todavia, a marca dos "movimentos contraditórios"3 ${ }^{3}$ dos anos 2000 e do governo do Partidos dos Trabalhadores se faz presente na separação da Secretaria do Ministério da Educação que tratava da Educação Média e Tecnológica. Dividindo politicamente a educação básica e a profissional.

Ademais, no processo político de implantação das Diretrizes Curriculares Nacionais para o Ensino Médio, o relator reeditou os fundamentos originais do Decreto de 1997 para o de 2004, não considerando o avanço das discussões políticas indicadas pelos grupos sociais que pleiteavam avanços rumo a um Ensino Médio baseado na Politecnia (RAMOS; FRIGOTTO; CIAVATTA, 2005).

Alguns outros aspectos claros de avanços no campo da educação foram a edição do Decreto $n^{\circ}$ 5478/2005 que criou o Programa de Integração a Educação Profissional ao Ensino Médio na Modalidade de Educação de Jovens e Adultos (PROEJA), bem como a criação e expansão das Universidades e da Rede Federal de Educação Profissional, Científica e Tecnológica, levando instituições importantes de produção do conhecimento para regiões afastadas do país. Nesse processo de expansão, e no caso da Rede Federal, de mudança de institucionalidade, o número de escolas, que passaram a ser campi passou de 140 em 2002 para 644 em 2016 (BRASIL, 2016).

Todavia, tanto os estudos acadêmicos, quanto as movimentações dos trabalhadores dessa rede, que realizaram 3 greves em 4 anos (2011, 2012, 2014 e 2015), denunciaram diversas contradições, denunciaram um processo de "precarização da rede" ${ }^{4}$, discutindo questões não apenas de infraestrutura, mas também questões políticas voltadas à democracia e autonomia da rede,

\footnotetext{
3 Referência ao título da obra de Moura (2013).

${ }^{4}$ A carta aberta de Murici (SINASEFE, 2011) divulgada na greve de 2011 denunciou muitas das faces da precarização da rede nesse processo de expansão, mas essa questão da precarização se tornou tão latente que tanto o Sinasefe quanto o Sindicato Nacional dos Docentes das Instituições de Ensino Superior (ANDES-SN) realizaram seminários regionais e nacionais para tratar do tema, tendo o Andes publicado um denso e extenso dossiê sobre a precarização nas Instituições Federais de Ensino Superior, sendo boa parte delas integrantes da Rede Federal.
} 
bem como adoção de medida de desmonte na carreira docente como as avaliações produtivistas ${ }^{5}$.

Junto a essas questões, cabe ressaltar alguns ataques as entidades sindicais, com a adoção de uma política de não negociar com entidades em greve, judicialização de greves e negociações com "sindicatos" ilegítimos para em última instância aprovar as medidas de retrocesso nas carreiras as quais os trabalhadores não tinham acordo.

Ainda no campo das políticas, o governo Dilma trouxe em 2011, como carro chefe para Educação Profissional o Programa Nacional de Acesso ao Ensino Técnico e Emprego (Pronatec), ${ }^{6}$ que representou um grande retrocesso ao apontar para a mercantilização da Educação e se basear nos princípios da educação instrumental (entenda-se mercantilização como a conversão de um direito em um serviço). Dessa feita, o estado pôde financiar a iniciativa privada com recursos públicos, por meio do PRONATEC (SILVA, 2015; MELO; 2015; OLIVEIRA, MENEZES, 2016; SANTOS, 2018).

Esse quadro, porém não é o final, soma-se a ele um período de estagnação econômica do país onde a ação proposta pelo governo Dilma para salvaguardar a economia e os dividendos dos grupos hegemônicos fora um pacote de austeridade à classe trabalhadora, que já sofre com alterações nas regras do seguro desemprego ${ }^{7}$ e nos cortes dos investimentos na educação.

Eis o cenário que compõe a conjuntura do $9^{\circ}$ Seminário Nacional de Educação (SNE) do SINASEFE, e, por conseguinte a elaboração do documento "Rede Federal de Educação Básica Profissional e Tecnológica: onde estamos e o que queremos". Sabendo que o cenário atual, de 2016, não pode nem receber com caracterizador os movimentos contraditórios, pois, após a ocupação da cadeira de Presidente por um candidato não eleito, através de um golpe político-jurídico-midiático, esse já demonstrou a adoção da agenda política que foi marca do retrocesso da década anterior.

\footnotetext{
${ }^{5}$ A Portaria MEC $n^{\circ}$ 554/13, de 20 de junho de 2013, que estabelece as diretrizes gerais para as avaliações de desempenho docente do EBTT e do magistério superior é um marco normativo dessa perspectiva produtivista, ao exigir critérios que podem ser associados a esse para balizar os processos institucionais de desenvolvimento na carreira docente. 6 Instituído pela Lei no 12.513 , de 26 de outubro de 2011.
}

7 Medida Provisória no 665, de 2014, convertida na Lei no 13.134, de16 de Junho de 2015. 


\section{SINASEFE - SINDICATO DE EDUCAÇÃO E A LUTA POR HEGEMONIA}

O Sinasefe enquanto entidade política de organização de trabalhadores tem historicamente atuado nas discussões nacionais referentes a Educação Profissional, tendo sua gênese nas Associações dos Servidores das Escolas Federais de $1^{\circ}$ e $2^{\circ}$ grau na década de 80 , e em sua Federação marcante era a presença dos trabalhadores das Escolas Técnicas Federais, referência na oferta de Educação Profissional no país.

Apresenta enquanto objetivos, com registro em seu Estatuto, ou seja, aprovado por maioria da categoria em Congresso, organizar e dirigir a luta dos servidores da Educação Básica, Profissional e Tecnológica, numa perspectiva classista e autônoma em busca de melhores condições de vida e de trabalho e enquanto princípios defende que as Instituições de Ensino devem ser públicas e garantam a oferta de um ensino laico, gratuito, de qualidade, com referência social e atenda aos interesses da classe trabalhadora (SINASEFE, 2015).

Tais disposições dizem muito sobre o propósito dessa entidade frente a discussão não apenas da Educação Profissional, mas também da Educação em termos gerais. Ao compreender que é necessário defender educação sobre os moldes supracitados, como forma de alcançar seus objetivos enquanto organização política, compreende a educação numa perspectiva emancipatória, e também enquanto campo de luta a ser disputado na sociedade pelos trabalhadores.

Nesse contexto, o Sinasefe passa a ter um papel importante no seio da sociedade para além daquele que deve cumprir enquanto entidade sindical o de defender os trabalhadores dos meios de degradação da vida - o de reunir os trabalhadores na construção e disputa de um projeto de escola baseado em seus interesses.

Em recente trabalho, Santos, Figueiredo e Azevedo (2016), discutem o papel dos sindicatos de educação na disputa por hegemonia em nossa sociedade: 
política dos sindicatos que os reúnem. Uma vez que, seu labor se constitui da ação pedagógica, tendo como lugar da venda da sua força de trabalho a escola, disputar um modelo de escola corresponde diretamente disputar sua forma de produzir dentro de uma sociedade que vive sob a lógica do capital. Portanto, a construção de um projeto de educação da classe trabalhadora, encontra nos sindicatos de educação uma convergência na disputa pela direção das instituições que formam a sociedade civil, ou seja, responsáveis pela esfera do convencimento, da forma de pensar na sociedade, disputas hegemônicas essenciais para Gramsci (SANTOS; FIGUEIREDO; AZEVEDO, 2016, p. 10).

Nessa esteira, entre os objetivos, princípios e papel assumido frente a sociedade, essa organização sindical ainda apresenta como compromisso a formação político-sindical da sua base política, os trabalhadores da Rede Federal. Tal compromisso condiz com a análise feita por Santos, Azevedo e Figueiredo (2016) quanto a um dos papéis dos sindicatos de educação "educar os trabalhadores através da vivência dos momentos associativos e de luta" (SANTOS; FIGUEIREDO; AZEVEDO, 2016, p. 10).

Dessa forma, é possível enxergar a centralidade da discussão acerca da Educação Tecnológica por parte dessa organização, ou pelo menos, que esta deveria ocupar. Reafirma-se então a seguinte concepção por parte do Sinasefe: "[...] situamos a educação tecnológica como potencializadora da construção de uma formação emancipatória da classe trabalhadora". (GUIMARÃES; SILVA, 2010, p.247)

Espaço específico para a discussão das concepções de educação por parte da base do Sinasefe, o Seminário Nacional de Educação, apesar de não ser instância deliberativa, tem se constituído nos últimos anos, a partir da grande quantidade de trabalhos apresentados e número de participantes ${ }^{8}$, como o lócus da produção de conhecimento de base para ação política no âmbito das políticas educacionais discutidas por este sindicato.

Apesar da tradição e do histórico de lutas frente a categoria da Educação Profissional, e por conseguinte da tradição no debate sobre educação e trabalho, Politecnia e formação integral, o Sinasefe não tinha nenhum documento base que servisse de registro do projeto de educação defendido por este, documento que apresentasse claramente diretrizes,

\footnotetext{
${ }^{8}$ O número de participantes foi de 60 em 2006 para 262 em 2015 (ano da aprovação do documento aqui discutido) e o número de texto foi de $18 \mathrm{em} 2010$ para 39 em 2013, segundo informações da assessoria de comunicação do Sindicato Nacional.
} 
concepções e princípios. Apenas resoluções de plenárias nacionais espalhadas em seus arquivos

A expansão da Rede Federal e sua nova institucionalidade trouxe outros reflexos ao Sinasefe para além dos problemas de precarização resultante do aligeiramento desse processo. Um deles foi a ampliação de sua base de representação, consequentemente sua receita e a participação dos trabalhadores em seus eventos. Outro reflexo, decorrente do alargamento da missão das Escolas que integram essa rede, ao unir agora ensino, pesquisa e extensão, aproximou sua base sindical da produção do conhecimento, o que fez com que essa base exigisse também de sua representação sindical maior qualidade e quantidade de produções teóricas.

Com esses movimentos, o $9^{\circ}$ Seminário Nacional de Educação, a partir de um largo debate através de um Grupo de Trabalho de Políticas Educacionais e Culturais, com encaminhamentos aprovados em Plenária Nacional, foi convocado e teve essa missão, aglutinar em um documento as concepções, diretrizes e princípios que são base para a Educação Profissional e para a Rede Federal que tanto almejam esses trabalhadores em educação.

\section{REDE FEDERAL de EdUCAÇÃo BÁsICA, PROFISSIONAL E TECNOLÓGICA: ONDE ESTAMOS E O QUE QUEREMOS}

Após a caracterização e historicização dos processos em curso que são fundamentais para a compreensão do contexto ao qual foi produzido o documento objeto de estudo desse trabalho, cabe-nos agora apresentar os pontos centrais, princípios e conceitos que contribuem com o debate histórico no campo contra-hegemônico que disputa um modelo de educação pautada na formação integral do indivíduo.

Ainda em sua apresentação, o documento demarca sua posição classista e a compreensão de que a educação, a formação humana, é um campo em disputa: 
as relações sociais de opressão, dominação ideológica e exploração. Neste ciclo de contradições, a conquista de instituições de ensino que contribuam para a emancipação do indivíduo requer transformações internas e externas ao ambiente acadêmico (SINASEFE, 2015a, p.07).

No que tange os princípios aos quais a Resolução se submete, destacamos os seguintes para continuidade do debate:

- Entendimento que a educação é um instrumento de transformação do indivíduo e da sociedade;

- Compromisso com a manutenção e ampliação do ensino público, gratuito e de qualidade;

- Priorização da referência social na classe trabalhadora para o desenvolvimento local;

- Valorização dos saberes populares;

- Erradicação de todas as formas de discriminação e preconceito (SINASEFE, 2015a, p.09).

Em seguida, apresentam um quadro conceitual diante desses princípios, do qual recortamos os seguintes conceitos para nossa discussão:

1. A educação deve ser pública, gratuita e de qualidade, em todos os níveis e modalidades. Isso porque é um direito inalienável da população brasileira, e não uma mercadoria ou um serviço. É, portanto, uma obrigação estatal;

2. A educação de qualidade não vem sendo acessível a todos e tem deixado marcas no Brasil. Enquanto perdurar a situação de atraso educacional, somamos nossa voz àquelas que reivindicam $10 \%$ do PIB para a educação laica, pública, gratuita e de qualidade;

3. Defendemos de forma intransigente que as nossas instituições sejam públicas, democráticas e transparentes no seu funcionamento, em suas deliberações, na definição e uso dos seus recursos, na destinação de sua produção intelectual e no seu acesso:

4. Autonomia plena nos moldes constitucionais onde as instituições que compõem a Rede inserem-se em nosso contexto social e dialogam com o conjunto de nossa sociedade: governos, partidos, dirigentes partidários e movimentos sociais; mas sem submissão a nenhum deles;

7. A indissociabilidade entre o ensino, a pesquisa e a extensão deve ser efetiva; e para tanto devem ser criadas as condições para esse fim;

8. Constituir redes de interação entre ensino, pesquisa e extensão para a formação de pessoas aptas a construir conhecimento, apresentar soluções para os problemas e agir sobre a realidade, possibilitando a melhoria da qualidade de vida das populações, principalmente aquelas em situação de vulnerabilidade social;

9. A interdisciplinaridade deve se dar por meio da sistematização e integração de experiências, articulando o trabalho funcional, acadêmico e científico;

12. A noção que não existe distinção entre docentes e técnicoadministrativos, como servidores públicos atuantes que são na área da educação; 
13. Revisão crítica dos ordenamentos regimental e estatutário, com vistas a propiciar decisões democráticas respaldadas em amplo debate. $E$ fundamental que a opinião de uma maioria encontre canais institucionais para se materializar em políticas na instituição como um todo. Isso só será possível se essa realidade se reproduzir também nos mais diversos campi. Assim, reafirma-se o compromisso com a elaboração de regimentos para os campi que também incorporem esse espírito (SINASEFE, 2015a, p. 11-12).

Apresentados os princípios e conceitos da presente Resolução, faz-se necessário pontuar como esses pontos colaboram para a discussão no campo contra-hegemônico da disputa por uma educação com formação integral, bem como analisar as mudanças e continuidades frente as diretrizes apresentadas no trabalho de Guimarães e Silva (2010).

Começando pelos pontos ausentes no presente documento que constavam do trabalho de Guimarães e Silva (2010), destacamos que três dessas ausências ocorreram diante de alterações nos marcos legais e a nova institucionalidade da Rede Federal: a criação de cursos de licenciatura plena; a obrigatoriedade da formação de nível superior aos docentes; e a equivalência legal entre os cursos de educação tecnológica de nível superior e as graduações correspondentes. O primeiro destes passou a ser oferta obrigatória dos Institutos Federais, enquanto o segundo (pelo menos na Rede Federal) e o terceiro ponto foram atingidos diante também de alterações na legislação ao longo dos anos. ${ }^{9}$

Outro ponto ausente, onde ocorreram avanços em alguns marcos legislativos, foi nas diretrizes para os cursos de educação tecnológica ofertados à população do campo. Tendo em vista a necessidade de ampliação da abrangência nesses avanços, uma vez que, eles estão reconhecidos legalmente no âmbito especifico do Programa Nacional de Educação na Reforma Agrária (PRONERA), ou nos regimentos e estatutos de algumas instituições, acreditamos que seria importante a abordagem desse ponto na Resolução.

Passadas as ausências, é importante destacar que a nova conjuntura, a nova institucionalidade e seus complexos movimentos trouxeram novas

\footnotetext{
${ }^{9}$ A Lei $n^{0} 13.415$, de 16 de fevereiro de 2017, alterou a LDB exigindo que a formação docente para atuar no ensino básico será de nível superior, já a Lei oㅜ 11.741, de 16 de julho de 2008, alterou a LDB no sentido da equivalência entre educação tecnológica de nível superior e suas graduações correspondentes.
} 
bandeiras de luta, uma delas, apresentada no documento é a Autonomia com diálogo social permanente. Partindo do contexto em que se dá a expansão da Rede com suas contradições brevemente abordadas no ponto do panorama histórico, o Sinasefe afirma em documento que "A Expansão da Rede, via de regra, se dá com atuação de agentes exógenos à comunidade e não a partir dessa" (SINASEFE, 2015a, p.15) e aponta o que chama de inúmeros processos de subordinação. Finaliza o ponto afirmando que para que haja autonomia é "[...]fundamental que a gestão seja radicalmente democrática"(SINASEFE, 2015a, p.17).

Com isso, o documento inova ao apontar uma série resoluções que buscam a ampliação dos espaços de decisão coletiva, do diálogo com os movimentos sociais, fortalecimento das decisões no âmbito institucional, autonomia para elaboração de currículos e criação de cursos conforme a realidade de cada instituição e fortalecimento dos colegiados frente aos órgãos executivos.

Outra nova demanda, que contribui para o debate no campo contrahegemônico e que advém da nova institucionalidade, é a do fortalecimento da atividade de pesquisa e da criação de condições adequadas ao desenvolvimento pleno dessa. Nesse tópico o documento apresenta a compreensão do sindicato em relação a pesquisa, entendendo esta como "[...] uma atividade artesanal, devendo estar vinculada ao desenvolvimento soberano de nosso país. [...]Precisamos refletir sobre isso de modo a valorizar e socializar em nossa instituição as condições objetivas para produzir ciência e tecnologia para o desenvolvimento social das regiões e do país"(SINASEFE, 2015a, p.21).

Compreende que para a obtenção desses fins é necessário jornadas de trabalho no ensino adequadas à produção científica e a criação de cursos de pós-graduação, "[...]como uma das prioridades institucionais, para atender princípios e demandas de educação voltada para a transformação social" (SINASEFE, 2015a, p.22).

Para além das ausências e inovações no documento, as permanências e seus diferentes enfoques apresentam importância central para o debate aqui demarcado. A primeira destas reside na forma de avaliação, onde o 
primeiro documento demarca a contrariedade ao sistema de avaliação por habilidades e competências (GUIMARÃES; SILVA, 2010), e a Resolução de 2015 apresenta a necessidade de instrumentos democratizados que não se submetam a lógica do mercado, apesar da legislação vigente e as propostas governamentais seguirem outro caminho, conforme já mencionamos, e como Frigotto (2011) pontua como um dos movimentos de continuidade das políticas da década anterior.

Outro ponto de permanência que consideramos como base para boa parte das propostas apresentadas em ambos os documentos, e como alicerce para o debate no campo contra-hegemônico, por se tratar de um dos fundamentos de sua metodologia e referencial teórico, é o trabalho como princípio educativo.

O trabalho enquanto princípio educativo, que na Resolução de 2015 recebe uma seção específica para conceituação, está no trabalho de Guimarães e Silva (2010) imersos nos pontos de defesa da Politecnia e da integração entre os cursos de educação tecnológica e a formação de nível fundamental e médio, pontos também defendidos pelo documento mais moderno, enquanto desdobramento da sua defesa do trabalho enquanto princípio educativo.

Com base nas compreensões por parte deste sindicato, já aqui apresentadas, da importância da educação como mediadora de uma realidade e instrumento de transformação social, defende que a Rede Federal deve ofertar uma educação voltada a emancipação da classe trabalhadora, que ao longo da história recebeu uma educação com vistas a ampliação das contradições da nossa sociedade, uma formação mecanicista voltada a entender os interesses do capital, que para seu desenvolvimento necessita de ampliar a espoliação dessa classe. Oferta essa, fruto da tradição de uma educação dual, com a separação entre trabalho técnico e intelectual.

Compreende então que para que a Rede possa garantir essa educação emancipatória, e romper a lógica do mercado historicamente atrelada as "Escolas Técnicas" que dão origem a essa rede, possibilitando então uma formação integral, politécnica (SAVIANI, 2003), essa educação deve ter o trabalho como princípio educativo, e por isso entende: 
O trabalho como princípio educativo significa colocar o trabalho como eixo central para democratizar o saber científico, tecnológico e histórico-crítico, a partir da compreensão de que o trabalho permeia todas as dimensões da vida humana. Assim, o trabalho assumido como princípio educativo, deve integrar-se com a ciência, a tecnologia e a cultura como base da proposta político-pedagógica e do desenvolvimento curricular.

Se ainda existem instituições educativas de acordo com a classe social, a função social da Rede, por meio da articulação entre ensino, pesquisa e extensão, é a formação integral, de intelectuais orgânicos para atuar na nova sociedade que surgirá, superando o academicismo e a profissionalização estreita (SINASEFE, 2015a, p.25).

Por fim, não passa despercebida, uma contribuição para o debate de uma formação que supere a lógica da divisão entre trabalho intelectual e manual, apresentada no quadro conceitual da Resolução de 2015, que é a noção de que não existe distinção entre trabalhador docente e trabalhador técnico-administrativo, entendendo ambos como trabalhadores que atuam no campo da educação, noção esta que apesar dos tensionamentos advindos da concepção hegemônica de divisão social do trabalho em nossa sociedade é uma questão central à vida política desse sindicato, uma vez que, representa trabalhadores docentes e técnicos da Rede Federal sob a mesma direção e entidade.

\section{PONTOS DE CHEGADA E NOVOS PONTOS DE PARTIDA}

Após a exposição das mudanças históricas na sociedade e no campo da educação no período histórico recortado, do papel do Sinasefe nesse campo de discussão, da mudança das suas resoluções para educação, educação profissional e para construção da rede de ensino que faz parte, seus significados, motivações e uma breve análise desse apanhando, apresentamos pontos de conclusão que ao seguir o processo dialético de produção do conhecimento se tornam ponto de partida para novas análises e novos trabalhos.

Em primeiro lugar, é necessário não olvidar da importância das movimentações dos trabalhadores e suas entidades sindicais frente ao processo produtivo e as mudanças históricas. Pois, apesar do 
enfraquecimento desses organismos com o avanço do pensamento neoliberal e dos padrões de produção flexível iniciados nos anos 70, ainda são uma categoria importante de análise, pois, como detentores de sua força de trabalho ainda são capazes de rejeitar as propostas do capital para as transformações na sociedade.

O campo da educação não se constitui como uma ilha frente as mudanças da sociedade e segue também esse pressuposto, dessa forma, é importante também estudar os movimentos dos trabalhadores em educação, ainda mais frente a especificidade de seu trabalho que é diretamente afetado pelas políticas educacionais vigentes em cada período.

Nesse sentido, no campo da educação profissional, os debates sobre políticas educacionais nessa área não devem deixar de lado os documentos, resoluções e ações dos trabalhadores, os quais, enquanto entidade sindical estão organizados junto ao Sinasefe. Precede então, somar às discussões teóricas e acadêmicas do campo da educação Profissional, o acúmulo produzido pelos debates nessa entidade.

No âmbito do Sinasefe, a partir dos documentos analisados podemos concluir que esses debates estão situados no campo contra-hegemônico da disputa por um modelo de educação, ou seja, aquele que entende a educação como instrumento de emancipação da classe trabalhadora e que deve ser ofertado com vistas a formação humana integral e não como instrumento do mercado espoliação do trabalho pelo capital. Concluímos isso a partir das disposições estatutárias, mas também dos elementos de permanência entre os documentos analisados (GUIMARÃES; SILVA, 2010; SINASEFE, 2015a) que tratam das resoluções deste sindicato para educação.

Quanto as Resoluções desse Sindicato analisadas, a primeira sendo fruto de um trabalho acadêmico publicado em 2010, e a última como documento aprovado em Plenária Nacional em 2015 resultado dos acúmulos dos Seminários Nacionais de Educação, podemos compreender a já mencionada permanência de princípios que as mantém no campo de luta por hegemonia e emancipação dos trabalhadores, exclusões diante das mudanças conjunturais e legais e pelo processo de debate na produção desta 
última, bem como inovações frente um novo momento histórico e uma nova institucionalidade. Sendo que estas apontam para a construção de uma educação e instituições que tratem o trabalho como princípio educativo, com base nos princípios da politecnia, com a superação da distinção entre trabalho intelectual e manual, em instituições que gozem de autonomia e radicalmente democráticas, que valorizam à pesquisa e extensão e as utilizam para o desenvolvimento humano.

Cumpre ainda ressaltar que, na comparação entre os dois documentos, existe um elemento que os distingue, que é o alcance das diretrizes, onde no primeiro estão diretrizes para o ensino tecnológico, o que há de se compreender como propostas que transbordem o lócus da representação sindical do Sinasefe, enquanto o mais moderno trata especificamente da Rede Federal, ou seja, trata do Ensino Profissional ofertado nesta e da organização e papel destas Instituições frente a sociedade.

Por fim, é necessário pontuar as possibilidades de mudanças recentes tanto nas resoluções quanto nas bandeiras de luta, uma vez que, consolidado o golpe político-jurídico-midiático no Brasil, e a assunção do poder de um governo não eleito pelo povo, o horizonte é de tentativa de supressão de direitos dos trabalhadores em geral, atingindo também o serviço público e a educação, mas também de um ataque às propostas de políticas educacionais voltadas a emancipação e formação do pensamento crítico nos sujeitos, haja vista os projetos de lei já citados em tramitação. Com tais mudanças é necessário também produzir análises dos movimentos dos trabalhadores e que subsidie esses movimentos, pafraseando a famosa tese de Karl Marx, é necessário compreender e mudar esse quadro (MARX,2008).

\section{REFERÊNCIAS}

ALVES, Giovanni. Trabalho e neodesenvolvimentismo - choque de capitalismo e nova degradação do trabalho no Brasil. Bauru: Canal 6, 2014.

ANTUNES, Ricardo. Os Sentidos do Trabalho: ensaio sobre a afirmação e a e a negação do trabalho. São Paulo: Boitempo, 2000. 
BRASIL. Ministério da Educação. Expansão da Rede Federal. Brasília, 2016. Disponível em: <http://redefederal.mec.gov.br/expansao-da-redefederal>. Acesso em: 05 jul. 2017.

DEMO, Pedro. Introdução à metodologia da ciência. São Paulo: Atlas, 2012.

FRIGOTTO, Gaudêncio. Os circuitos da história e o balanço da educação no Brasil na primeira década do século XXI. Revista Brasileira de Educação. Rio de Janeiro, v. 16, p. 235-254, 2011.

GUIMARÃES, Maurício; SILVA, Maria Cristina Madeira da. As políticas de educação tecnológica para o Brasil do século XXI: reflexões e considerações do Sinasefe. In: MOLL, Jaqueline; Et al (org.). Educação Profissional e Tecnológica no Brasil contemporâneo. Porto Alegre: Artemed, 2010, p 244-251.

MARX, Karl. Contribuição à crítica da Economia Política. São Paulo: Expressão Popular, 2008.

MOURA, Dante. Ensino médio e educação profissional nos anos 2000: movimentos contraditórios. In: MOURA, Dante (Org.) Produção de conhecimento, políticas públicas e formação docente em educação profissional. Campinas: Mercado das letras, 2013. p. 141-200.

Mudanças na sociedade brasileira dos anos 2000 limitadas pela hegemonia do neoliberalismo: implicações para o trabalho e para a educação. In: MOURA, Dante Henrique (org.). Produção do conhecimento, políticas públicas e formação docente em educação profissional. Campinas: Mercado das Letras, 2013a. p.109-140.

OLIVEIRA, Elelnice Gomes de; MENEZES, Rommel Rennê Santos de. Desafios e contradições do Programa Nacional de Acesso ao Ensino Técnico e Médio (PRONATEC). In: Antonia Abreu de Sousa et al (Org.) As interfaces do mundo do trabalho: Educação, práxis social e formação dos trabalhadores. Curitiba: CRV, 2016. p. 223-236.

SILVA, Danilma de Medeiros. Desvelando o PRONATEC: uma avaliação política do programa. 2015. 168 f. Dissertação (Mestrado em Educação) Universidade Federal do Rio Grande do Norte, Natal, 2015.

MELO, Ticiane Gonçalves Sousa de. O Pronatec e o processo de expansão e privatização da educação profissional no Brasil. 2015. $138 \mathrm{f}$. Dissertação (Mestrado em Educação Profissional) - Instituto Federal de Educação, Ciência e Tecnologia do Rio Grande do Norte, Natal, 2015.

RAMOS, Marise; FRIGOTTO, Gaudêncio; CIAVATTA, Maria. A gênese do decreto no 5.154/2004: um debate no contexto controverso da democracia. In: FRIGOTTO, G. et al. (Orgs.). Ensino médio integrado: concepções e contradições. São Paulo: Cortez, 2005. p. 21-56. 
SANTOS, Shilton Roque dos. Avaliação participativa de resultados sociais do PRONATEC Campo. 2018. 186 f. Dissertação (Mestrado em Educação Profissional) - Instituto Federal de Educação, Ciência e Tecnologia do Rio Grande do Norte, Natal, 2018.

SINASEFE. ESTATUTO. Aprovado no 29 Congresso Nacional do Sinasefe realizado no período de 26 a 29 de março de 2015 em João Pessoa/PB. 2015. Disponível em:

http://www.sinasefe.org.br/v3/index.phpoption=com_docman\&task=doc_downl oad\&gid=1818\&ltemid=61. Acesso em: 20 ago. 2016 .

SINASEFE. Carta aberta de Murici. Maceió. 2011. Disponível em: <http://www.sinasefe.org.br/antigo/Carta_de_Murici.pdf>. Acesso em: 20 ago. 2016.

\section{SINASEFE. Rede Federal de Educação Básica, Profissional e}

Tecnológica: Onde estamos e o que queremos? Aprovado na 132a Plena Nacional do Sinasefe, em 05 de julho de 2015. 2015a Disponível em:

http://www.sinasefe.org.br/v3/index.php?option=com_content\&view=article\&id $=1500: 2015-12-11-05-03-14 \&$ catid=1 :latest-news\&ltemid=75. Acesso em: 20 ago. 2016.

SANTOS, Shilton R; FIGUEIREDO, Etiene F.; AZEVEDO, Marcio A. O papel dos sindicatos de (trabalhadores em) educação na disputa por hegemonia na sociedade civil. In: I JOINGG - JORNADA INTERNACIONAL DE ESTUDOS

E PESQUISAS EM ANTONIO GRAMSCI, Fortaleza. Anais... Fortaleza, 2016. v. 1. p. $1-14$.

SAVIANI, Demerval. O choque teórico da politecnia. Revista Educação, Trabalho e Saúde. Rio de Janeiro: EPSJV/FIOCRUZ, v. 1, p. 131-152, 2003. 